\title{
Emergency fall Response of Nurses Visiting the Homebound Elderly in the Community: An Experience-Based Study
}

\author{
Hyesun Park ${ }^{1}$, Sunyoung $\mathrm{Lim}^{2}$, Ryewon $\mathrm{Ma}^{3}$ \\ ${ }^{1}$ Ph.D, Dept. of Red Cross College of Nursing, Chung-Ang University, Republic of Korea, \\ april1007@naver.com \\ ${ }^{2}$ Assistant Professor, Dept. of Nursing, Baekseok Culture University, Republic of Korea, \\ isokety@bscu.ac.kr \\ ${ }^{3}$ Assistant Professor, Dept. of Nursing, Kyungnam University, Republic of Korea, \\ mrw4023@Kyunganm.ac.kr \\ Corresponding author: Sunyoung Lim
}

\begin{abstract}
The purpose of this study is to conduct a qualitative case study of visiting nurses caring for the elderly at home. In this study, various experiences are identified among case managers in emergency situations with regards to falls. It was conducted to explore experience as a case manager in emergency situations. Data were collected through in-depth interviews with five visiting nurses living in both the Seoul and Gyeonggi regions. The collected data were analyzed qualitatively to identify experiences, strategies, and issues between research cases. In addition, by categorizing them according to emergency management with regards to falls, this study derives six final categories. Furthermore, in verifying the validity of the study, participant review and peer review of the study results and interpretation were conducted. As a result of this study, a total of six categories were derived: requests for visiting nurses of the home-based elderly to understand the characteristics of these home-based seniors, requests for assessment of high-risk groups in emergency management for visiting nurses of the home-based elderly, request to identify abnormal symptoms in emergency situations for visiting nurses of the home-based elderly, responsibility for emergency management of for visiting nurses of the home-based elderly, interaction requests for information sharing in emergency situations for visiting nurses of the homebased elderly, request to build confidence through repeated training of visiting nurses for the at-home elderly. Based on the results of this study, it was found that there is a need to lay the foundation for the development of a fall prevention program for visiting nurses who take care of the elderly at home, and to find ways to reduce falls during emergency treatment.
\end{abstract}

Keywords: Homebound Elderly, Visiting Nurse, Falls, Case Management, Qualitative Case Study

\section{Introduction}

Korea has entered an aged society with about $14.3 \%$ of the elderly population in 2018 , and is expected to become a super-aged society with $15.7 \%$ in $2020,20 \%$ in 2025 , and $41 \%$ of the elderly population with almost 90 years of life expectancy - by 2060[1].

The term "at-home elderly" refers to the general elderly who live at home in the local community, and it refers to all seniors with the exception of the elderly in institutional care and the elderly in long-

Received: May 11, 2021; $1^{\text {st }}$ Review Result: June 26, 2021; $2^{\text {nd }}$ Review Result: August 14, 2021

Accepted: September 30, 2021 
term hospitalization[2]. In addition, the at-home elderly in the community are classified as frail seniors; due to their experienced difficulties of independently performing in daily life - due to aging, disease, or disability, and so on - they live in their own homes while receiving various help from the local community, long-term care insurance for the elderly, and care for the elderly. They also receive support from services and home-based aged welfare services[3][4].

The number of elderly recipients of long-term care insurance is increasing; most of them have underlying diseases and are at high risk of safety-related accidents such as falls[5]. Safety management awareness and education are both very important factors in minimizing damage caused by emergency accidents such as falls.

Most of the elderly who use domestic emergency medical centers are the at-home elderly in the local community[6]. Recently, the number of emergency medical center visits by the elderly living alone and elderly couples without a guardian have been increasing[7]. As such, the increasing use of emergency medical centers by the at-home elderly emphasizes the need for various methods to maintain their health.

According to the Korea Disease Control and Prevention Agency, falls make up more than half of bodily injuries experienced by senior citizens aged 65 or older[8]. The rate of falls increases when the age of the individual is higher and their education level is lower. Older adults who have experienced falls may experience secondary complications from old age and underlying diseases, such as hip fractures and head injuries[9]. Fall injuries are also reported to occur more in people with a history of previous fractures. In older adults, preventive education and mediation should be conducted. Needless to say, the role of caregivers is important.

Not only is it difficult for the elderly to recover from the physical damage resulting from a fall[10], but the complications from falls are more severe than in younger people, which can even lead to death[11]. The increase in medical visits among the elderly living in the community[7] and the occurrence of more than half of falls from physical injuries[8] is a very important task because it creates new health problems for the elderly and lives with long-term complications[9]. However, since most of these accidental falls are preventable, it is very important to provide the correct information and systematic education for visiting nurses - who are caregivers for the at-home elderly - in advance. It is important that the assessments of accident risk factors are included. However, it is difficult for these visiting nurses taking care of the at-home elderly to predict how to detect and manage emergency situations such as falls. There is no systematic emergency response yet. Therefore, it is necessary to study how the visiting nurses caring for the elderly at home cope with and manage emergency fall situations.

\section{Methods}

\subsection{Research Design}

This study was conducted to explore how home elderly visiting nurses perform case management in emergency fall situations, and it also sought to explore the issues that emerged during this process. In order to achieve this purpose, a qualitative case study method was used. It is the best way to understand the various issues that visiting nurses at home experience as case managers in emergency fall situations. It also aimed to create understanding of the experiences case managers deal with in emergency fall situations, particularly within each of the following systems: individuals (case managers), institutions, and communities. This was judged to be an appropriate research method. For the study design, an individual case study design was adopted to identify experiences of coping as a case manager in these emergency fall situations regarding the at-home elderly. Interview questions were adopted through literature review and confirmed by three researchers who conducted qualitative research in the doctoral program. The interview was based on the research question, "What experiences do you have in coping 
with emergency situations of falls as a visiting nurse?" and "How would you describe your experiences when dealing with these emergencies?" The research participants were asked to talk in detail about what happened in each process of emergency response, focusing on the cases they wanted to talk about. Additional research questions were asked according to the contents of the interview. The sub-questions are as follows:

- First, in the event of an emergency due to a fall, can you tell us about your experience of how, and with what information, to whom?

- Second, can you tell us what your role is to manage a fall emergency?

- Third, what knowledge and skills are required to perform a role for managing an emergency caused by a fall?

- Fourth, what do you think is the most important part for managing an emergency due to a fall in visiting nursing?

\subsection{Research Subject and Data Collection}

Using a purposeful sampling method, the study participants selected 5 case managers working as visiting nurses for the at-home elderly in the Seoul and Gyeonggi regions. The study participants who met the theoretical qualification or competence to provide relevant information and data on the subject of this study were selected; this selection occurred among case managers who were visiting nurses to the at-home elderly for more than 3 years and managed fall emergencies [Table 1]. Data collection was conducted through individual in-depth interviews from March 14 to April 28, 2021. The location and time of the in-depth interview was conducted according to the wishes of the study participants, and the interview time was about 60 to 90 minutes per session. Interviews were conducted once or twice on the basis of unstructured open-ended questions; these questions regarded the experiences of visiting nurses coping with emergency fall situations of the at-home elderly, and were conducted until the data were saturated.

[Table 1] Characteristics of the Respondents

\begin{tabular}{|c|c|c|c|c|}
\hline & Age(years) & Sex & $\begin{array}{c}\text { Total clinical } \\
\text { experience (years) }\end{array}$ & $\begin{array}{c}\text { Visiting Nurse Experience } \\
\text { (years) }\end{array}$ \\
\hline 1 & 49 & F & 14 & 4 \\
\hline 2 & 39 & M & 8 & 5.2 \\
\hline 3 & 41 & F & 6 & 3.5 \\
\hline 4 & 45 & M & 13 & 3 \\
\hline 5 & 44 & F & 10 & 3 \\
\hline
\end{tabular}

\subsection{Data Analysis and Ethical Consideration}

The interview was recorded with the consent of the study participants, and the recorded content was transcribed without deletion or modification to form a transcript. After reading and grasping the overall content of the transcript, the researchers conducted line-by-line analysis to thematically focus on expressions similar to the words expressed by the study participants. By analyzing this and categorizing it according to the emergency management of falls, this study finally derived six categories. These cat egories were derived with regards to the emergency management of visiting nurses to the at-h ome elderly. In addition, to verify the validity of the study, participant reviews and peer reviews were conducted on the research results and the interpretation. During this process, the purpose and method of the study, the risks and benefits of participating in the interview, and the confidentiality measures were 
all explained by the researcher to the participants. Participants were promised that - should they eventually wish to withdraw from the study - consent could be withdrawn at any time during or after the interview, without any repercussions. Participants were also informed that the collected data would be used solely for research purposes, and that the contents mentioned by the participants would be kept in strict confidentiality. Participants who voluntarily consented to participate in the study submitted written consent to participate in the study. During the interview, personally identifiable information was transcribed with symbols, and the recorded file was deleted after transcription was completed. In this study, care was taken not to infringe on the human rights of the participants during the entire research process. After the interview, certain cases were given.

\section{Results}

As a result of analyzing the raw data collected through in-depth interviews, it was found that similarities and diversity coexist in the emergency response of the elderly visiting nurses in the community who participated in the study.

\subsection{Requirement of Visiting Nurses to Understand the Characteristics of At-Home Elderly}

This category indicates that at-home elderly visiting nurses needed to understand the debilitating physical and cognitive changes necessary for emergency management of falls. Visiting nurses recognized that it is necessary for emergency management to understand the characteristics of the athome elderly, and that they can be exposed to emergency situations such as falls at any time due to decreased physical function. A residual function assessment was found to be a necessary factor for understanding the at-home elderly, as well as their remaining physical, mental, and social functions and characteristics with various functional states.

"When a 92-year-old woman (long-term care grade 3) was visited in her home in the absence of a guardian, she was lying in bed complaining of hip pain. When asked if she had a fall, she could not give a clear answer, and the right side of the hip was swollen compared to the left. She was an elderly person taking aspirin. I have had the experience of going and meeting the guardian and returning after taking over. This person needs physical function (partial assistance for daily living ability and full assistance for going out and using the toilet), cognitive function (short-term memory impairment), and behavioral changes (the pattern of trying to go to the bathroom alone at night was observed and repeated even when given attention the patient was a high-risk subject for falling because they tried to move alone. Medication was added for the patient's behavioral control disorder, but they lost their sense of balance and the risk of falling increased. Medication adjustment was subsequently required in addition to usual nursing treatment (none - the caregiver's income was not constant, so treatment is burdensome)."

"A 78-year-old woman (long-term care grade 4) was going down the 1.5-floor stairs (sloping stairs in a row house) to go for a walk at 3 p.m. She subsequently lost her balance and fell down the stairs, as her legs had lost their strength. She complained of severe pain (suspected fracture) in the right hip joint, so she called 119 and went to the nearest emergency room for treatment while a guardian came and took over. This person was being monitored for chronic disease (diagnosed with and taking medication for osteoarthritis since 7 years ago, as well as being diagnosed with and taking medication for hypertension since 20 years ago), physical function (needs assistance in daily life performance ability), cognitive function (normal), and behavioral change (irregular sleep)."

"An 80-year-old woman (a low-income senior living alone in a one-person household) was on her way to go to the supermarket to buy snacks, and her legs became weak. She fell down the stairs of a townhouse and began to complain of back pain afterwards. I have experienced that a guardian came and took over while we went for treatment. The patient was monitored closely for chronic disease (diagnosed 
with and taking medication for hypertension and diabetes mellitus since 15 years ago), physical function (needed assistance for daily living ability), cognitive function (mild cognitive impairment: MMSE 22 points), and behavioral changes (irregular sleep). The patient received 527,158 won for her single-person household to cover basic livelihood assistance."

\subsection{Request for Assessment of High-Risk Groups in Emergency Management At-Home Elderly Visiting Nurses}

This category indicates that visiting nurses for the at-home elderly should know of any underlying diseases and whether the patient is taking drugs, and they should also have practical knowledge to manage emergency fall situations. This category also explains that visiting nurses for the at-home elderly should be aware that there are a variety of ways to prevent falls. It also explains visiting nurses recognition of the importance of managing high-risk subjects in case of emergency for the at-home elderly.

"Despite taking the medication, the arthritis was severe and the pain was severe. Because the subject is also aware of this part, the pain gets worse if he stands still. For this reason, the strength in his legs decreased while walking as usual, and he lost his balance and fell down the stairs. This person lives in a row house, and there is no elevator. They were seriously injured and I believe it was damage to the right hip. They had severe arthritis and it was difficult for them to move on a regular basis, so I had a lot of knowledge about the risk of falls. I knew everything because the subject had cognitive ability issues but this happened on the stairs of the house they lived in, so I can't tell them to move, and I don't know what to do about this."

"This person has high hypertension, and diabetes mellitus, and they have been taking medication for 15 years. They have mild cognitive impairment, but they are able to communicate and perform daily activities. The fall occurred while they were going down the stairs of a townhouse in order to go to the supermarket to buy a snack. They complained of severe back pain. In this case, he has hypertension and diabetes mellitus. He has also been taking medication for a long time, so he is classified as an individual with a high risk of falling and is specially managed. The patient was old and couldn't stay at home, and when they went down the stairs, they didn't have the energy, so it must have put a strain on their back"

"This person usually goes to the day care center during the day, and even when the fall occurred, he fell on the sloped road while going to the day care center. In this case, too, the patient - who has been taking drugs for a long time - is at high risk of falling, and every time the caregiver visits, he assesses the physical factors and always explains and educates about falls. It hurts my heart so much that this happens even though the person is aware of it and is constantly educated on the fact that it is difficult to recover when a fall occurs in old age. This leads to a lot of suffering."

\subsection{Request to Identify Abnormal Symptoms in Emergency Situations of Visiting Nurses for the At- Home Elderly}

This category explains home-based senior visiting nurses' inclusion of the assessment and intervention of subjects; this was specifically done with the intention of providing first aid to these individuals in emergency situations. This category (after an emergency fall) explains the practice of visiting nurses distinguishing between an at-home elderly's physical abnormalities due to bodily injury. It elaborates on the importance of preventing additional bodily damage by performing emergency measures, such as immobilizing the suspected fracture site or stopping the bleeding at an injury site in the event of a fall.

"The subject complained of severe pain in both hip joints. In this situation, I made the area around the subject safe and asked where she was in pain. I called 119 right away. Then, I checked to see if she 
could move her limbs lightly, but her couldn't move both legs. So, her neck and back were supported, and the subject was placed in a supine position. It was explained that her head would not move, and a hard splint was placed near her hip joint, secured with a towel. The ring, watch, and so on were all removed just in case. Given that the subject complained of severe pain in both hips, it was assumed that she may have surgery later, so did not eat any food so as not to observe pre-operation fasting. Later, 119 came and she was taken to the hospital."

"She complained of severe pain in her left hip,' she said. Her grandmother was able to go about her daily life, but she was diagnosed with osteoporosis 10 years ago and took medication. She was also diagnosed with hypertension and diabetes mellitus, and she has been taking medication for 20 years. She said she was going to have to check and make sure she was okay, so she called 119 and informed her agency of the situation."

"She is cared for as a high risk person for falls, but this time she slipped over a sill while going to the bathroom, and when I visited, she was lying in bed complaining of hip pain. I did a body assessment without going to the hospital, and the right hip part was swollen in comparison to the left. She said, 'There was swelling, it hurt a lot, and I can't move.' A hip fracture was then suspected. She said that she couldn't even eat because her energy was so low, so I measured her blood sugar first. Then, 119 was called and she went to the hospital for an examination."

\subsection{Responsibility for Emergency Management of Home Elderly Visiting Nurses}

This section explains how visiting nurses acquire the knowledge and skills to minimize bodily injury and recognize the importance of performing first aid in the emergency situation of a fall for at-home elderly individuals. The visiting nurse explained that in emergency situations (falls) for the elderly at home, treatment should be performed to minimize secondary fractures and injuries by maintaining an immobile posture for the fall patient. This section organizes patient information related to safe patient transport and emergency situations, and delivers information regarding hospital transport.

"She fell as she was going down the stairs of the townhouse, and she collapsed as she lost strength in her legs. She has hypertension and diabetes mellitus, and is on medication, so I asked her where she was hurting, loosened her clothes around her waist, and immobilized her. This person was carried and moved, and a splint was not used as this would cause further damage. She remained in place and had blood pressure and blood sugar checks. After that, I reported the progress to the institution. However, the hospital treatment was not performed right away, so I had to stay with the patient."

"She was the one who fell down while going down a sloping road and complained of pain in this part of her left wrist. So I suspected a fracture of the left wrist. Also, he was diagnosed with osteoarthritis 20 years ago and had experience taking medication, and he had hypertension and diabetes mellitus, so he had been taking medication for 25 years. She placed the subject in the desired comfortable position after the fall, and used a towel to wrap and support an item that could be used as a splint. I checked her fingers frequently to see if blood circulation was good and whether or not there was any swelling. I also checked for any other injuries, and encouraged her to stay as motionless as possible. Then, 119 arrived, told me about the patient's condition, and quickly moved them to the hospital, but he had to wait a long time in the hospital emergency room, so I stayed with him. It took so much time, so I reported it to the agency. In such a situation, there is no choice for someone who lives without a guardian or who lives far away in general, but it is often difficult for me in my position."

"She rolled down her stairs and fell down the steps after losing her balance and her leg strength. At this time, she complained of severe pain in both hip joints. In this situation, I made the area around the subject safe and asked where she was in pain. I called 119 right away. Then, I checked to see if she could move her limbs slightly, but she couldn't move either of her legs. So, the subject's neck and back were supported and she was placed in a supine position. It was explained to her that her head would not move, 
and a hard splint was placed near her hip joint and secured with a towel. I removed her bracelet, ring, watch, and so on just in case. As the subject complained of severe pain in both hips, it was assumed that she might have vertebral spine surgery. Later, 119 came and took us to the hospital. I went to the emergency room and told the medical staff everything I knew about the patient's medication and known conditions, and she said that she needed a guardian to be with her during the examination, so I stayed with her."

\subsection{Interaction Requests for Information Sharing in Emergency Situations of Visiting Nurses for the At-Home Elderly}

This category explains that visiting nurses need clear information to manage emergency situations (falls) for the elderly at home. In an emergency situation (fall) for the at-home elderly, visiting nurses explained the need to manage the situation by interacting with the institution through the process of requesting help. It was also explained that there is a need for a communication method framework for systematic information delivery in emergency situations (falls) for the elderly at home.

"I reported to the emergency system of the local public health center because I needed to take prompt action through comprehensive physical/cognitive assessment in the absence of the guardian. In addition, in order to explain the results of the comprehensive assessment to the guardian and the necessity of visiting the hospital, it is reported to the institution through accurate communication with the guardian as this includes an accurate grasp on the usual daily living performance, cognitive status, and drug taking status compared to the time of the subject's assessment. I think that is important, and when 119 comes, it takes over the present and past history. This is because the delivery of clear information is a way to properly assess the patient and provide quick treatment."

"In an emergency such as an elderly person's fall, I notify the center and the guardian, and then connect with the hospital that has been agreed upon with the guardian. In addition, in the case of the elderly, they do not think deeply about safety-related situations and tend to ignore or hide them, so careful observation of the subject is required. For this reason, the body assessment is detailed. We report those issues to the center and communicate with the caregiver."

"There are many cases where communication is difficult due to the deterioration of physical/cognitive abilities as a result of old age. It is also required to designate a treatment decision-maker for the patient, and communicate whether or not information is shared with other family members. Although a hip fracture was suspected after the fall, the first son exclaimed that the subject should not be taken to the hospital, and the second daughter insisted that the subject go to the hospital - despite her brother's request - and do first aid. Because this exists, I want to make those parts clear."

\subsection{Requirement to Build Confidence Through Repeated Training of Visiting Nurses for the At-Home Elderly}

This category explains that repeated training is necessary for effective management of emergency situations (falls) by visiting nurses for the elderly at home.

"When we train nurses and nursing assistants (care assistants) at the center, what we pay a lot of attention to is repetition in learning. Staff changes frequently, and emergencies are literally emergencies, so even a nurse who is a medical professional may be impatient and make mistakes when such a situation arises. Because I believe that emergency education is so ingrained in the body that it is only effective if treatment is given right away in an actual emergency situation, I and the director of the center are trying to develop emergency response skills with that mindset. In my case, after first aid for the elderly at home, there is a part where I once again thought about being a medical professional and a nurse."

"I was always worried about whether I would be able to do well in an actual emergency while 
receiving training on how to deal with emergency situations in theory at the center. One time, during her visit, an old woman was walking down a sloping road to the Senior Citizen's Center and fell into a ditch. She complained of severe pain in her left hip. At that time, I made the area around the subject safe and made sure that her limbs could move. There was a long stick like a son-in-law in my bag, so I used it as a splint and placed it near the left hip joint, fixing it with a towel. I called 119 in advance, and I did not move until 119 came. I took the items out of the bag, measured her blood pressure and blood sugar, and 119 arrived and gave me a handover. Fortunately, grandmother did not have major surgery or a dangerous situation, so she was discharged from the hospital, and I still visit her. Every time I see her, I feel proud and confident."

"I think the at-home elderly people and their caregivers have high expectations of us. In other words, I think of it as trust in medical personnel, but I always think that these expectations should not be disappointed. So, I read and re-check the emergency training guidelines. You need to recognize it accurately in theory so that you can perform it without being too hasty in an actual emergency. In an emergency, we are always trembling, but we try to calm them down and reassure them. If we believe and trust those aspects, we will be very proud."

\section{Discussion}

This study was confirmed by an in-depth interview method to understand the experiences and meanings of emergency fall situations of visiting nurses caring for the at-home elderly. In case of a fall emergency, the role to be played in emergency situation management, difficulties in managing emergency situations, and emergency situation management among visiting nurses were reviewed. As a result of this study, a total of six categories were derived:

- requests for visiting nurses of the home-based elderly to understand the characteristics of these homebased seniors

- requests for assessment of high-risk groups in emergency management for visiting nurses of the homebased elderly

- request to identify abnormal symptoms in emergency situations for visiting nurses of the home-based elderly

- responsibility for emergency management of for visiting nurses of the home-based elderly

- interaction requests for information sharing in emergency situations for visiting nurses of the homebased elderly

- request to build confidence through repeated training of visiting nurses for the at-home elderly

First, visiting nurses of the home-based elderly answered that it was necessary to understand the characteristics of the home-based elderly in emergency situations while visiting and providing care to them. It was found that the characteristics of the at-home elderly in the community were to understand cognitive changes along with physical weakness, and to recognize that they could be exposed to a fall or an emergency situation - at any time during daily life at home. This is because in the case of a fall for the at-home elderly, vision problems, gait disturbances, decreased muscle strength of the lower extremities, cognitive decline[12], and physical and psychological factors[13] are influencing factors. In this study, it was found that while visiting the subjects, for visiting nurses of the at-home elderly observed physical and cognitive changes from the most basic items and understood the drug intake status of the elderly related to underlying disease. A residual function assessment[3][4] was found to be a necessary factor for understanding the elderly at home, specifically in regards to understanding the physical, mental, and social functions and characteristics remaining with various functional states. Therefore, it is an important factor for visiting nurses to understand the characteristics of the elderly at home to manage emergency situations such as falls.

In addition, in the emergency management of for visiting nurses of the home-based elderly, the high- 
risk group assessment request was found as a category. For the at-home elderly in the local community, assessment of the high-risk group is an essential element[14]. Since it causes a fall risk and can lead to a serious accident, it is all the more important to monitor the status of the at-home elderly who are a part of the high-risk group for falls[15]. Therefore, it is thought that visiting nurses should be well aware of the basic underlying diseases of the home elderly and whether they are taking any drugs; they should also prepare standards for identifying signs of high-risk groups and provide consistent guidelines in emergency education on how to respond in emergency situations.

Next, in an emergency situation regarding visiting nurses of the home-based elderly, a request existed in identifying abnormal signs. This included the fact that the disease overlaps with the decrease in physical function due to the process of aging. Organ function is significantly reduced, resulting in the manifestation of the symptoms of chronic disease, and this is a complex combination of disease and aging. As a result of this syndrome, the elderly has increased risk factors such as functional deterioration and falls, causing many clinical problems[16]. It can be seen that it is important to promptly implement first aid in a hospital to prevent further bodily damage or injury.

In addition to this, the demand for responsibility of emergency management for visiting nurses of the home-based elderly, the request for interaction of information sharing in emergency situations, and the need to build confidence through repeated training are interconnected, from safe patient transport and emergency situations to hospital transport. It is connected to the importance of communication methods for systematic information delivery. It is also connected with the indication of the need for quick first aid management, specifically by interacting with visiting nurses in the process of requesting help from the institution in a fall emergency. Management of emergency situations - such as falls of the elderly at home - requires continuous capacity building, and visiting nurses who feel a sense of responsibility as a first aid provider must provide repeated education to make up for deficiencies; continuous study is required[17], and this is a result that can appear due to the self-confidence of visiting nurses.

\section{Conclusions}

This study was conducted to understand the experience and meaning of emergency response to falls of visiting nurses to the home-based elderly in the community. As a result of this study, a total of six categories were derived:

- requests for visiting nurses of the home-based elderly to understand the characteristics of these homebased seniors

- requests for assessment of high-risk groups in emergency management for visiting nurses of the homebased elderly

- request to identify abnormal symptoms in emergency situations for visiting nurses of the home-based elderly

- responsibility for emergency management of for visiting nurses of the home-based elderly

- interaction requests for information sharing in emergency situations for visiting nurses of the homebased elderly

- request to build confidence through repeated training of visiting nurses for the at-home elderly.

In the future, it is necessary to develop an education program to deal with emergency situations such as falls for visiting nurses who provide care for the at-home elderly, and to comprehensively understand the characteristics of the at-home elderly in case of an emergency (fall) as well as an approach including the attributes of the at-home elderly. In emergency situations such as falls among visiting nurses in the local community, it is necessary to reduce the incidence of falls in the elderly and lead a healthy life through expanded roles and multidisciplinary integrated management. In addition, the significance of this study lies in that it presented the necessity and evidence of a systematic management plan for emergency fall situations of the at-home elderly in the community. 


\section{References}

[1] http://kostat.go.kr/portal/korea/kor_nw/1/1/index.board?bmode=read\&aSeq=385322, Sept 28 (2020)

[2] H. Y. Lee, Welfare of the elderly, YoungPoong Books, (2004)

[3] S. Y. Lim, S. O. Chang, S. J. Kim, H. J. Kim, J. Choi, M. S. Park, Nurses' management of nursing home residents' remaining functional ability: concept development, Journal of Korean Academy of Fundamentals of Nursing, (2014), Vol.21, No.1, pp.57-68, https://doi.org/10.7739/jkafn.2014.21.1.57

[4] S. Lim, S. Chang, Ego-integrity management of residents in nursing homes: a concept analysis based on the method by Walker and Avant, Journal of Korean Gerontological Nursing, (2018), Vol.20, No.2, pp.97-108, DOI: https://doi.org/10.17079/jkgn.2018.20.2.97

[5] Y. H. Park, Fall Risk Assessment in the Community-Dwelling Elderly, Journal of Korean Gerontological Nursing, (2004), Vol.6, No.2, pp.170-178.

[6] J. Hwang, S. Kim, M Won, D. Heo, J. Ahn, D. Shin, Factors of Revisit of Older Adult that Emergency Departments, Journal of Digital Contents Society, (2019), Vol.20, No.12, pp.2555-2563, DOI : 10.9728/dcs.2019.20.12.2555

[7] H. Kim, Y. Park, The effects of discharge planning for the elderly with pulmonary disease in the emergency room, Journal of Korean Critical Care Nursing, (2014), Vol.7, No.1, pp.24-32, UCI : G704-SER000003931.2014.7.1.00

[8] http://www.kdca.go.kr/contents.es?mid=a20203070000, Apr 6 (2021)

[9] H. Jung, S. Kim, S. Lee, S. Kim, G. Cho, M. Kim, J. Lee, C. Han, Relating factors to severe injury from outdoor falls in older people, Geriatrics \& gerontology international, (2018), Vol.18, No.1, pp.80-87, DOI: 10.1111/ggi.13144

[10] C. Lukaszyk, L. Harvey, C. Sherrington, L. Keay, A. Tidemann, J. Coombes, L. Clemson, R. Ivers, Risk factors, incidence, consequences and prevention strategies for falls and fall-injury within older in-digenous populaitons: A systematic review, Australian and New Zealand Journal of Public Health, (2016), Vol.40, No.6, pp.564-568, DOI: $10.1111 / 1753-6405.12585$

[11] M. Jeon, M. Gu, J. Yim, Comparison of Walking, Muscle Strength, Balance, and Fear of Falling Between Repeated Fall Group, One-time Fall Group, and Nonfall Group of the Elderly Receiving Home Care Service, Asian nursing research, (2017), Vol.11, No.4, pp.290-296, DOI: 10.1016/j.anr.2017.11.00

[12] H. Lee, T. Lee, K. Tae, A Study on the Prediction of Fall Factors for the Elderly Living in the City, Journal of Rehabilitation Welfare Engineering \& Assistive Technology, (2018), Vol.12, No.1, pp.46-52, https://doi.org/10.21288/resko.2018.12.1.46

[13] R. Leonhardt, C. Becker, M. Groß, A. S. Mikolaizak, Impact of the backward chaining method on physical and psychological outcome measures in older adults at risk of falling: a systematic review, Aging Clinical \& Experimental Research, (2020), Vol.32, No.6, pp.985-997, DOI: 10.1007/s40520-019-01459-1

[14] Y. Ju, H. Lee, Correlation of cognitive function and fall-risk related behavioral factors, Therapeutic Science for Rehabilitation, (2018), Vol.7, No.2, pp.41-50, https://doi.org/10.22683/tsnr.2018.7.2.041

[15] S. Sato, S. Demura, S. Shin, Assessing a personal and population fall risk profile in Japanese community-dwelling elderly, Japan Journal of Test and Measurement in Health and Physical Education, (2012), Vol.11, No.1, pp.49-55, https://doi.org/10.14859/jjtehpe.11.49

[16] K. I. Kim, Frailty: A Core Geriatric Concept, Journal of the Korean Geriatrics Society, (2010), Vol.14, No.1, pp.1-7, DOI: https://doi.org/10.4235/jkgs.2010.14.1.1

[17] Y. Park, E. Kong, Y. Park, Triage nurses' work experiences in emergency department: a qualitative research, Journal of Muscle and Joint Health, (2018), Vol.25, No.3, pp.176-186, https://doi.org/10.5953/JMJH.2018.25.3.176 